\title{
COMPARATIVE STUDY OF PHENOLIC ACIDS FROM UNDERGROUND PARTS OF RHEUM PALMATUM L., R. RHAPONTICUM L. AND R. UNDULATUM L.
}

\author{
Ewa Medyńska, Helena Danuta Smolarz \\ Chair and Department of Pharmaceutical Botany, Medical University \\ Chodźki 1, 20-093 Lublin, Poland \\ e-mail: smolarz@am.lublin.pl
}

(Received: February 11, 2005. Accepted: April 6, 2005)

\begin{abstract}
In three species of Rheum L. genus growing in Poland the composition of phenolic acids was determined. By 2D-TLC method the following acids were identified: ellagic, chlorogenic, gallic, protocatechuic, homoprotocatechuic, caffeic, $\alpha$-resorcilic, p-hydroxyphenylacetic, p-hydroxybenzoic, p-coumaric, syringic, vanillic and ferulic. There are no substantial qualitative differences among the complex of phenolic acids in the investigated species. The RP-HPLC method was used for quanitative determination of phenolic acids. The amount of individual phenolic acids ranged between $2.2 \mu \mathrm{g} / \mathrm{g}$ and $147.8 \mu \mathrm{g} / \mathrm{g}$ in air-dry rhizome. The content of ferulic acid is the highest in all the examined cases. The total amount of the tested phenolic acids in Rheum undulatum L., R. palmatum L., and $R$. raponticum L. was respectively $346.4 \mu \mathrm{g} / \mathrm{g}, 229.8 \mu \mathrm{g} / \mathrm{g}$, and $195 \mu \mathrm{g} / \mathrm{g}$.
\end{abstract}

KEY WORDS: Polygonaceae, Rheum, rhizome and roots, phenolic acids, 2D-TLC, RP-HPLC.

\section{INTRODUCTION}

Rheum genus belonging to the family Polygonaceae is represented by about 70 species. Only three out of the 70 species are growing in Poland. They are: $R$. palmatum, $R$. rhaponticum ( $R$. rhabarbarum), $R$. undulatum.

$R$. palmatum is cultivated for therapeutic properties of roots. The petioles of Rheum rhaponticum and R. undulatum are used for their nutritious properties.

The main components of Rheum are: antraquinones (emodin, aloe-emodin, chrysophanol, physcion, rhein and its derivatives (Chai et al. 1998; Liu 1999; Li et al. 2000); diantrones (Oshio et al. 1974); stilbenes (resveratrol, piceatannol, rhapontigenin) and its derivatives (Matsuda et al. 2001; Kashiwada et al. 1986; Kageura et al. 2001); naphtalenes (Tsuboi et al. 1977); chromones, phenylbutanones (Kashiwada et al. 1986).

Among them, there are compounds possessing chemotaxonomic attributes. The presence of rhaponticin in R. rhabarbarum is the marker differentiating $R$. rhaponticum from R. palmatum. Most phenolic compounds may be used as chemotaxonomic markers.

The aim of this paper is the comparative study of phenolic acids obtained from underground parts of three Rheum species cultivated in Poland. Phenolic acids of the mentioned species were ivestigated in Rheum palmatum and
R. undulatum. P-coumaric acid and gallic acid and its dervatives were detected (Kashiwada et al. 1986; Abe et al. 2000 ), and gallic acid was isolated from $R$. undulatum (Kageura et al. 2001; Matsuda et al. 2001).

\section{MATERIAL AND METHODS}

\section{Plant material}

The rhizome and roots of three specimens of Rheum were used in this study: Rheum palmatum was from Herbapol (Lublin, Poland); Rheum undulatum and Rheum rhaponticum $\mathrm{L}$. were collected in the Botanical Garden of the University Maria Curie-Skłodowska in Lublin in 2003.

Rheum rhaponticum and Rheum undulatum are deposited in the Department of Pharmaceutical Botany, Medical Academy in Lublin.

\section{Extraction and isolation}

The air-dried plant material $(50 \mathrm{~g})$ were extracted three times (15 min. for each extraction) with $80 \%$ methanol in ultrasonic bath. The obtained extract was purified and free phenolic acids fractions were isolated in classical way (Ibrahim and Towers 1960). The processes of acid hydrolysis of phenolic acids conjugated with sugar were performed according to Schmidtlein and Herrmann (1975). The 
TABLE 1 . The occurrence of phenolic acids in rhizome and roots of Rheum palmatum $\mathrm{L}$., Rheum undulatum $\mathrm{L}$. and Rheum rhaponticum $\mathrm{L}$.

\begin{tabular}{|c|c|c|c|c|c|c|c|c|c|c|c|}
\hline \multirow{2}{*}{ No. } & \multirow{2}{*}{ Acids } & \multirow{2}{*}{ Commonly used names } & \multicolumn{3}{|c|}{ R.palmatum } & \multicolumn{3}{|c|}{ R. undulatum } & \multicolumn{3}{|c|}{ R. rhaponticum } \\
\hline & & & A & $\mathrm{B}$ & $\mathrm{C}$ & $\mathrm{A}_{1}$ & $\mathrm{~B}_{1}$ & $\mathrm{C}_{1}$ & $\mathrm{~A}_{2}$ & $\mathrm{~B}_{2}$ & $\mathrm{C}_{2}$ \\
\hline 1 & galloylgallic & ellagic & + & + & - & + & + & - & + & + & - \\
\hline 3 & 3,4,5-trihydroxybenzoic & gallic & - & + & + & + & + & + & + & + & + \\
\hline 4 & 3,4-dihydroxybenzoic & protocatechuic & + & + & + & + & + & + & + & + & + \\
\hline 5 & 3,4-dihydroxyphenylacetic & homoprotocatechuic & - & + & + & - & + & + & - & + & + \\
\hline 7 & 3,5-dihydroxybenzoic & $\alpha$-resorcylic & + & - & - & + & - & - & + & - & - \\
\hline 8 & 4-hydroxyphenylacetic & p-hydroxyphenyl-acetic & + & + & - & + & + & + & + & + & - \\
\hline 9 & 4-hydroxybenzoic & p-hydroxybenozic & + & + & + & + & + & + & + & + & + \\
\hline 10 & 4-hydroxycinnamic & p-coumaric & + & + & + & + & + & + & + & + & + \\
\hline 11 & 3,4,5-trimethoxybenzoic & syringic & + & + & + & + & + & + & + & + & + \\
\hline 12 & 3-methoxy-4-hydroxybenzoic & vanillic & + & + & + & + & + & + & + & + & + \\
\hline 13 & 3-methoxy-4-hydroxycinnamic & ferulic & + & + & + & + & + & + & + & + & + \\
\hline
\end{tabular}

$\mathrm{A}$ - free phenolic acids fraction; $\mathrm{B}$ - after acid hydrolysis; $\mathrm{C}-$ after alkaline hydrolysis; (+) - present; (-) - absent

alkaline hydrolysis were performed with $\mathrm{Ba}(\mathrm{OH})_{2}$ in reductive medium $\mathrm{NaBH}_{4}$ (Świątek and Dombrowicz 1987).

The samples of free phenolic acids (A), phenolic acids liberated by acid hydrolysis (B), and phenolic acids liberated by alkaline hydrolysis (C) were dissolved in $10 \mathrm{~mL}$ of ethanol and investigated by 2D-TLC and HPLC methods.

\section{D-TLC qualitative determination of phenolic acids}

Separation and identification of phenolic acids (samples A-C) was performed on $10 \times 10 \mathrm{~cm}$ cellulose plates (Merck, Darmstadt, Germany). After spotting of the phenolic acids standard solution or plant extract the plates were developed in DS horizontal chambres (Dzido 1993) in phases according to Smolarz and Waksmundzka-Hajnos (1993). After drying, the chromatograms were observed in UV light $(\lambda=254 \mathrm{~nm})$ before and after treatment with ammonia vapour. Derivatisation was performed by spraying with one of the two reagents: diasotized sulphanic acid in $20 \%$ sodium carbonate solution or $2 \%$ aqueous solution of ferric chloride.

\section{HPLC quantitative determination of phenolic acids}

The quantitative determination of nine main phenolic acids was carried out using Knauer (Germany) Model nr $\mathrm{K}-1001$ liquid chromatograph with $20 \mu \mathrm{L}$ sample injector (Rheodyne, Cotati, CA, USA) and UV detector (UV-VIS) operated at $254 \mathrm{~nm}$.

The stainless-steel column $200 \times 4.6 \mathrm{~mm}$ J.D. was filled with $5 \mathrm{~nm}$ Hypersil ODS (Shandon, Cheshire, UK). The isocratic mobile phase consisted of methanol-water $(25: 75)$ with $5 \% \mathrm{v} / \mathrm{v}$ acetic acid. The flow rate was $1 \mathrm{~mL} / \mathrm{min}$. Chromatography was performed at room temperature. The chromatograms were recorded with Chroma 2000 program.

\section{RESULTS}

From the qualitative investigations carried out by two-dimensional thin-layer chromatography method it follows that rhizome and roots of the investigated raw material contain derivatives of benzoic, cinnamic and phenylacetic acids. They are the following acids: ellagic, chlorogenic, gallic, protocatechuic, homoprotocatechuic, caffeic, $\alpha$-resorcilic, p-hydroxyphenylacetic, p-hydroxybenzoic, p-cou- maric, syringic, vanillic and ferulic. The mentioned acids are comonly present both in elementary and linked state except $\alpha$-resorcylic acid and chlorogenic acid, which are present only in free state, and caffeic and homoprotocatechuic which are detected only in bounded and liberated form. The distribution of these compounds is shown in Table 1 .

The data of chromatographical (2D-TLC) analysis show no substantial qualitative differences among groups of phenolic acids from the investigated species.

RP-HPLC method was used for quanitative determinations of phenolic acids. The amount of each phenolic acid was interpreted from calibration curve obtained for concentrations of standard solution of acid containing 80, 100 and $120 \%$ of the expected level of this compound in the extracts. It was found that the calibration plots for all acids were of the type $y=b x+a$, where $y$ is the peak area, $x$ is the concentration of the standard, $a$ is the intercept of the plot on $y$ axis, and $b$ is its slope. The errors in slope and intercept of the regression line, standard deviation and detection limit are shown in Table 2.

The amount of individual phenolic acids in $R$. palmatum (in $\mathrm{A}+\mathrm{B}+\mathrm{C}$ fractions) ranged between $21.2 \mu \mathrm{g} / \mathrm{g}$ of air dry rhizome for syringic acid and $67.7 \mu \mathrm{g} / \mathrm{g}$ for ferulic acid (Fig. 1). The minor component of $R$. undulatum is p-hydroxybenzoic acid $(7.2 \mu \mathrm{g} / \mathrm{g})$ and major component is ferulic acid (147.8 $\mu \mathrm{g} / \mathrm{g}$ ) (Fig. 2). The rhizome and roots of $R$. rhaponticum are also rich in ferulic acid $(77.7 \mu \mathrm{g} / \mathrm{g})$ and poor in p-hydroxybenzoic $(2.2 \mu \mathrm{g} / \mathrm{g}$ ) (Fig. 3). In all cases the content of ferulic acid is the highest. Besides, the ferulic acid, concentration of p-coumaric acid and protocatechuic acid is significant in all investigated species. Homoprotocatechuic and vanilic acids occurred in the highest amounts in R. palmatum.

We show that phenolic acids concentration is higher in linked than free state. $R$. rhaponticum contains $35.1 \mu \mathrm{g} / \mathrm{g}$ of free phenolic acids, $R$. palmatum $-45.9 \mu \mathrm{g} / \mathrm{g}$ and $R$. undulatum $-48.8 \mu \mathrm{g} / \mathrm{g}$; higher content of acids linked with sugar $(69.8 \mu \mathrm{g} / \mathrm{g} 90.8 \mu \mathrm{g} / \mathrm{g}$ and $90.9 \mu \mathrm{g} / \mathrm{g}$ respectively) and most acids as ester derivatives ( $R$. palmatum $-105 \mu \mathrm{g} / \mathrm{g} ; R$. rhaponticum - $111.5 \mu \mathrm{g} / \mathrm{g} ;$ R. undulatum $(185.6 \mu \mathrm{g} / \mathrm{g})$.

On the basis of the obtained results one can expect that $R$. palmatum and $R$. undulatum contain similar amounts of phenolic acids in free state and bound with sugars, whereas 
TABLE 2. Data of quantitative determination of phenolic acids.

\begin{tabular}{|c|c|c|c|c|}
\hline Phenolic acid & Detetection limit (L.o.d) (ng) & Standard deviation & Regresion line & Errors in slope and intercept \\
\hline gallic & 13 & 0.9928 & $y=6133 x-12.6$ & $\begin{array}{l}b=6133 \pm 16.5 \\
a=-12.6 \pm 2.4\end{array}$ \\
\hline protocatechuic & 10 & 0.9454 & $y=8944 x+39.7$ & $\begin{array}{l}b=8944 \pm 30.5 \\
a=39.7 \pm 25.2\end{array}$ \\
\hline caffeic & 12 & 0.9992 & $y=2973 x+12$ & $\begin{array}{l}\mathrm{b}=2973 \pm 12.1 \\
\mathrm{a}=12 \pm 1.8\end{array}$ \\
\hline p-hydroxybenzoic & 16 & 0.9998 & $y=13.8 x+14.8$ & $\begin{array}{l}\mathrm{b}=13.8 \pm 0.4 \\
\mathrm{a}=14.8 \pm 23.8\end{array}$ \\
\hline p-coumaric & 60 & 0.9988 & $y=3.6 x+555$ & $\begin{array}{l}\mathrm{b}=3.6 \pm 1.15 \\
\mathrm{a}=555 \pm 56.6\end{array}$ \\
\hline syringic & 11 & 1.0130 & $y=342 x+7.7$ & $\begin{array}{l}b=342 \pm 5.9 \\
a=7.7 \pm 0.87\end{array}$ \\
\hline vanillic & 10 & 0.9940 & $y=11044 x+37$ & $\begin{array}{l}b=11044 \pm 19.3 \\
a=37 \pm 18.6\end{array}$ \\
\hline ferulic & 64 & 1.0004 & $y=3.9 x+8.8$ & $\begin{array}{l}\mathrm{b}=3.9 \pm 0.92 \\
\mathrm{a}=8.8 \pm 46.1\end{array}$ \\
\hline
\end{tabular}

$R$. rhaponticum contains more of these compounds after alcaline hydrolysis.

Large total amounts of the nine investigated acids was detected in underground parts of $R$. undulatum $(346.4$ $\mu \mathrm{g} / \mathrm{g}$ ), whereas in $R$. palmatum $-229.80 \mu \mathrm{g} / \mathrm{g}$, and $R$. rhaponticum L. $-195 \mu \mathrm{g} / \mathrm{g}$.

The main active components of genus Rheum L. are antraquinones, but the presence of other phenolic compounds such as stilbenes and phenolic acids occuring in these spe- cies in lower concentration have a synergic influence on the activity of these species.

\section{LITERATURE CITED}

ABE I., SEKI T., NOGUCHI H., KASHIWADA Y. 2000. Galloyl esters from Rhubarb are potent inhibitor sof squalene epoxidase, a key enzyme in cholesterol biosynthesis. Plant. Med. 66 (8): 753-756.

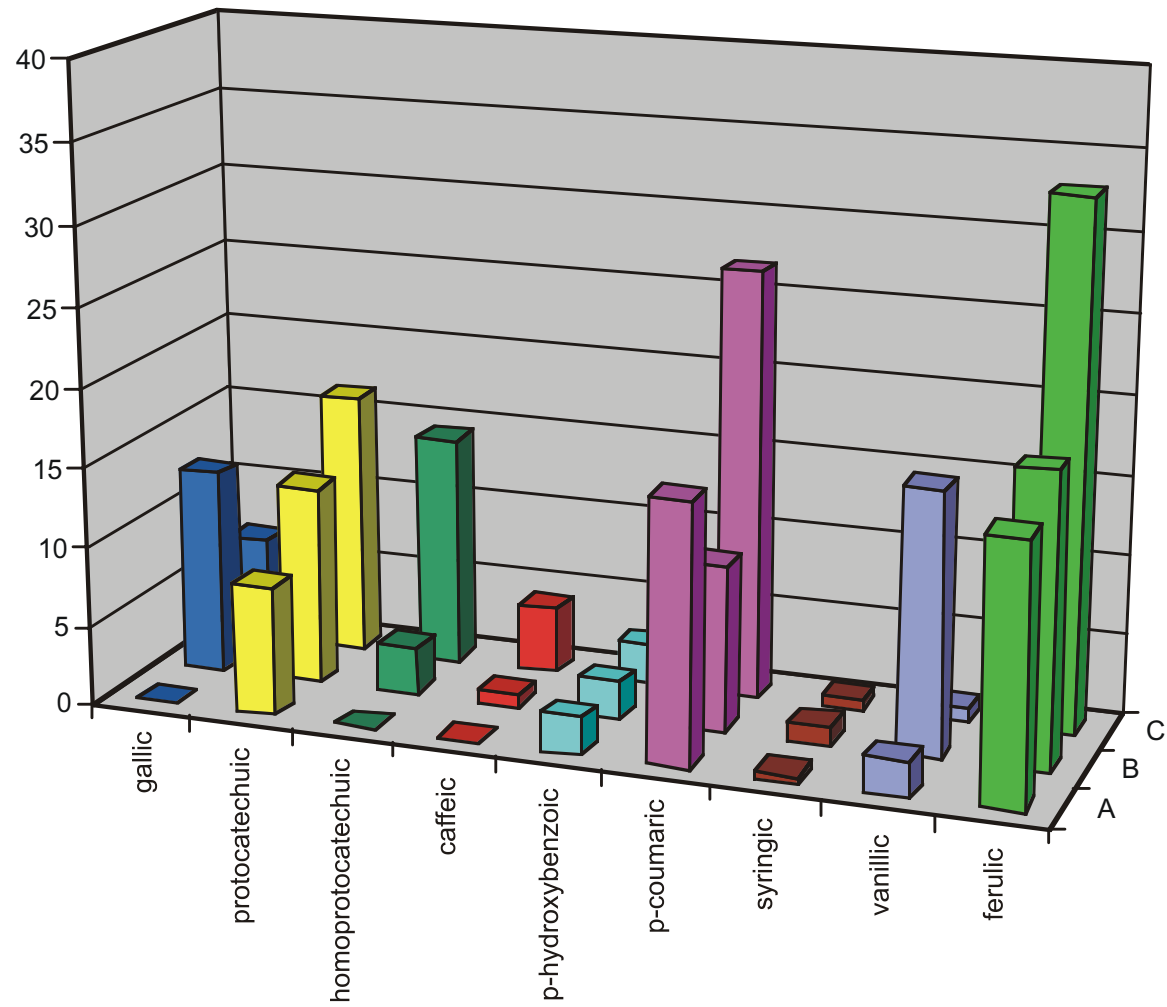

Fig. 1. Content of phenolic acids in R. palmatum L. (in $\mu \mathrm{g} / \mathrm{g}$ air-dried underground parts). 

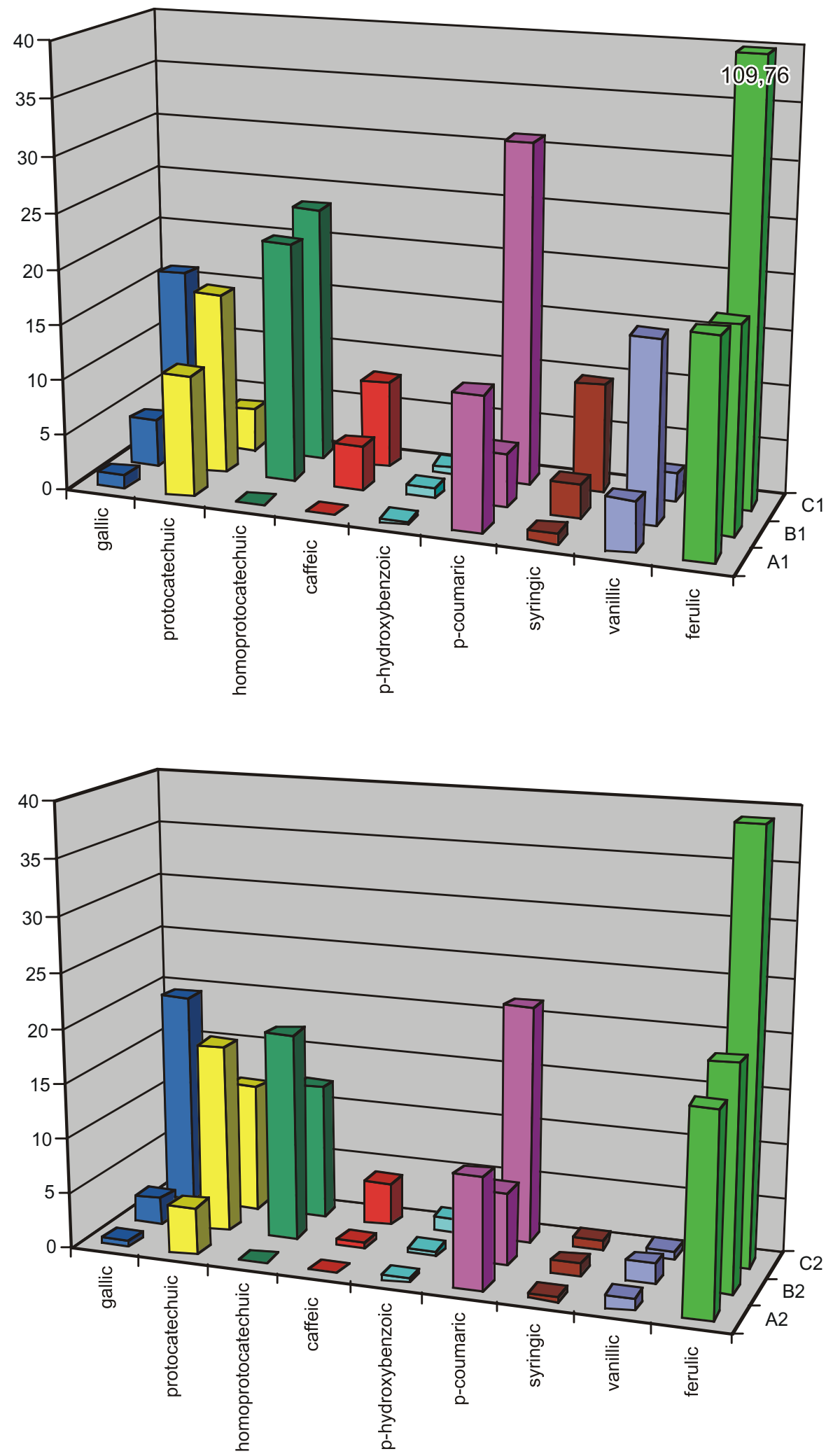

Fig. 2. Content of phenolic acids in $R$. undulatum $\mathrm{L}$ (in $\mu \mathrm{g} / \mathrm{g}$ air-dried underground parts).

Fig. 3. Content of phenolic acids in $R$. rhaponticum $\mathrm{L}$. (in $\mu \mathrm{g} / \mathrm{g}$ air-dried underground parts).
CHAI Y.F., JI S.G., WU Y.T., LIANG D.S., XU Z.M. 1998. The separation of anthraquinone derivatives of Rhubarb by miceller electrokinetic capillary chromatography. Biomed. Chromatogr. 12: 193-195.

DZIDO T.H. 1993. The horizontal DS-Chamber and its Modifications. J.P. Chromatogr. 6: 78.

IBRAHIM R.K., TOWERS G.H. 1960. Identification by chromatography of plant phenolic acids. Arch. Biochem. Biophys. 87: 125.
KAGEURA T., MATSUDA H.,MORIKAWA T., TOGUCHIDA I., HARIMA S., ODA M., YOSHIKAWA M. 2001. Inhibitors from Rhubarb on lipopolysaccharide-induced nitric oxide production in macrophages: structural requirements of stilbenes for the activity. Bioorg. Med. Chem. 9: 1887-1893.

KASHIWADA Y., NONAKA G.I., NISHIOKA I. 1986. Tannins and related compounds. XLVII. Rhubarb. Isolation and characterization of new p-hydroxyphenylbutanones, stilbenes and gallic acid glucosides. Chem. Pharm. Bull. 34 (8): 3237-3243. 
LI W., CHAN C.L., LUENG H.W. 2000. Liquid chromatography-atmospheric pressure chemical ionization mass spectrometry as a tool for the characterization of anthraquinone derivatives from Chinese herbal medicine. J. Pharm. Pharmacol. 52: 723-729.

LIU C.L., ZHU P.L., LIU M.C. 1999. Computer-aided development of a high-performance liquid chromatographic method for the determination of hydroxyanthraquinone derivatives in Chinese herb medicine rhubarb. J. Chromatogr. A. 857: 167-174.

MATSUDA H., MORIKAWA T., TOGUCHIDA I., PARK J.Y., HARIMA S., YOSHIKAWA M. 2001. Antioxidant constituents from Rhubarb: structural requirements of stilbenes for the activity and structures of two new anthraquinone glucosides. Bioorg. Med. Chem. 9: 41-50.

OSHIO H., IMAI S., FUJIOKA S., SUGAWARA T., MIYAMOTO M., TSUKUI M. 1974. Investigation of Rhubarbs. III.
New purgative constituents, sennosides E and F. Chem. Pharm. Bull. 22 (4): 823-831.

SCHIMDTLEIN H., HERRMANN K. 1975. Quantitative analysis for phenolic acids by thin layer chromatography. J. Chromatogr. 115: 123-126.

SMOLARZ H.D., WAKSMUNDZKA-HAJNOS M. 1993. Dwodimensional TLC of phenolic acids on celullose. J. P. Chromatogr. 6: 278-281.

ŚWIĄTEK L., DOMBROWICZ E. 1987. Fenolokwasy w farmakopealnych gatunkach z rodzaju Polygonum L. Farm. Pol. 420: 7-8. (in Polish with English summary)

TSUBOI M., MINAMI M., NONAKA G.I. 1977. Studies on Rhubarb (Rhizoma Rhei). IV. Naphtalene glycosides. Chem. Pharm. Bull. 25 (10): 2708-2712. 